\title{
THE ELECTRICAL PROPERTIES OF ALUMINUM FOR CRYOGENIC ELECTROMAGNETS
}

\author{
R. J. CORRUCCINI
}

U. S. DEPARTMENT OF COMMERCE NATIONAL BUREAU OF STANDARDS 


\section{THE NATIONAL BUREAL OF STANDARDS}

The National Bureau of Standards is a principal focal point in the Federal Government for assuring maximum application of the physical and engineering sciences to the advancement of technology in industry and commerce. Its responsibilities include development and maintenance of the national standards of measurement, and the provisions of means for making measurements consistent with those standards; determination of physical constants and properties of materials; development of methods for testing materials, mechanisms, and structures, and making such tests as may be necessary, particularly for government agencies; cooperation in the establishment of standard practices for incorporation in codes and specifications; advisory service to government agencies on scientific and technical problems; invention and development of devices to serve special needs of the Government; assistance to industry, business, and consumers in the development and acceptance of commercial standards and simplified trade practice recommendations; administration of programs in cooperation with United States business groups and standards organizations for the development of international standards of practice; and maintenance of a clearinghouse for the collection and dissemination of scientific, technical, and engineering information. The scope of the Bureau's activities is suggested in the following listing of its four Institutes and their organizational units.

Institute for Basic Standards. Electricity. Metrology. Heat. Radiation Physics. Mechanics. Applied Mathematics. Atomic Physics. Physical Chemistry. Laboratory Astrophysics. * Radio Standards Laboratory: Radio Standards Physics; Radio Standards Engineering.** Office of Standard Reference Data.

Institute for Materials Research. Analytical Chemistry. Polymers. Metallurgy. Inorganic Materials. Reactor Radiations. Cryogenics. * Office of Standard Reference Materials.

Central Radio Propagation Lahoratory.* Ionosphere Research and Propagation. Troposphere and Space Telecommunications. Radio Systems. Upper Atmosphere and Space Physics.

Institute for Applied Teclinology. Textiles and Apparel Technology Center. Building Research. Industrial Equipment. Information Technology. Performance Test Development. Instrumentation. Transport Systems. Office of Technical Services. Office of Weights and Measures. Office of Engineering Standards. Office of Industrial Services.

* NBS Group, Joint Institute for Laboratory Astrophysics at the University of Colorado.

** Located at Boulder, Colorado. 


\title{
NATIONAL BUREAU OF STANDARDS Eechnical Note 218 Issued August 30, 1964
}

\section{THE ELECTRICAL PROPERTIES OF ALUMINUM FOR CRYOGENIC ELECTROMAGNETS}

\author{
R. J. Corruccini \\ Cryogenics Division \\ National Bureau of Standards \\ Boulder, Colorado
}

NBS Technical Notes are designed to supplement the Bureau's regular publications program. They provide a means for making available scientific data that are of transient or limited interest. Technical Notes may be listed or referred to in the open literature.

For sale by the Superintendent of Documents, U. S. Government Printing Office

Washington, D.C. 20402

Price: $30 \notin$ 

ABSTRACT

1. INTRODUCTION

2. THE IMPERFECTION RESISTIVITY

3, THE LATTICE RESISTIVITY

4. SIZE EFFECTS

4. 1 In Zero Field

4. 2 In Magnetic Fields 10

5. MAGNETORESIST ANCE

5. 1 Discussion -

6. THE FIGURE OF MERIT _... 17

7. DISCUSSION

8. APPENDIX. EFFECTS OF PLASTIC DEFORMATION - - - - 20

ADDENDUM -

9. REFERENCES 

The Electrical Properties of Aluminum for Cryogenic Electromagnets

\section{R. J. Corruccini}

The published data for the ideal resistivity and the magnetoresistivity of aluminum have been correlated. It is shown that both properties can be calculated for the limited ranges of temperature and purity that are of importance for aluminum cryogenic electromagnets from the residual resistivity ratio alone. Empirical functions are given for these properties, and sample calculations are given of the figure of merit for a particular aluminum solenoid relative to the same solenoid using water-cooled copper.

\section{INTRODUCTION}

The well-known fact that the electrical resistivity and hence the Joule loss in a conductor may be greatly reduced by cooling to cryogenic temperatures has led to various cooled electromagnets for laboratory research [1]. However, the designing of these magnets, all of small size, was influenced mainly by various special considerations rather than by economic factors. On the other hand, emphasis by Post [2] of the economic advantages of cryogenic electromagnets for applications where high fields must be maintained throughout large spaces, such as nuclear fusion devices or particle accelerators, has made it clear that careful projections of costs and performance are needed. It is not yet clear what the relative roles of superconducting and normal-conducting magnets will ultimately be in such applications. This paper is concerned only with the latter. 
In rating normal-state cryogenic electromagnets it has become conventional to compare the total power expenditure (Joule loss in the magnet conductor plus refrigerator power) with the power expenditure of a water-cooled copper electromagnet (Joule loss only, neglecting the power expenditure for cooling). The following formula defines a figure of merit on this basis.

$$
\phi[\mathrm{T}] \equiv \frac{\rho[\mathrm{T}, \mathrm{H}]}{\rho_{\mathrm{Cu}}[300]}\left[1+\frac{\mathrm{T}_{\mathrm{a}}-\mathrm{T}}{\eta \mathrm{T}}\right] .
$$

The first term in the bracket gives the contribution of the Joule loss; the second gives the contribution of the refrigerator power. Here $\mathrm{T}_{\mathrm{a}}$, the temperature to which the refrigerator exhausts heat, may be taken as $300^{\circ} \mathrm{K}$. The factor $\eta$ is the overall efficiency of the refrigerator relative to ideal thermodynamic efficiency. It may be taken to be about 0.3 [3]. The room temperature resistivity of copper, $\rho_{\mathrm{Cu}}[300]$, is $1.7 \mu \mathrm{ohm}-\mathrm{cm}$. The resistivity of the cryogenic conductor, $\rho[\mathrm{T}, \mathrm{H}]$, may be approximated as the sum of the imperfection or "residual" resistivity $\rho_{0}$, the lattice or "ideal" resistivity $\rho_{i}=f(T)$, and the magnetoresistance $\rho_{H}$.

$$
\rho[\mathrm{T}, \mathrm{H}]=\rho_{\mathrm{o}}+\rho_{\mathrm{i}}+\rho_{\mathrm{H}} \cdot
$$

The lattice resistivity is ordinarily assumed to be a unique function for a given metal. However, in order to retain the simple form of equation (2) it may be necessary to assume it to be a weak function of $\rho_{0}$. Also the magnetoresistance may be a function of both the temperature and $\rho_{0}$. The optimum operating temperature is selected by minimizing $\phi$. 
Using a mean resistivity appropriate for the conductor in an electromagnet producing $10^{5}$ gauss, only five metals have been found to give calculated values of $\phi$ less than unity. Sodium [2] and aluminum are outstanding if sufficiently pure and may give values approaching 0. 1 .

Copper [2] gives a minimum value of about 0.5 , and lithium is perhaps about the same. Indium falls between. The optimum temperatures âre roughly as follows: $30^{\circ} \mathrm{K}$ for copper, $15-20^{\circ}$ for aluminum, $10^{\circ}$ for sodium and lithium, and below $4^{\circ}$ for indium. These estimates are based on large extrapolations of $\rho_{\mathrm{H}}$ for sodium, lithium, and indium and as sume that $\rho_{0}$ can be lowered to any desired extent by purification, regardless of what may actually have been achieved to date.

Of the two leading contenders, aluminum has superior strength, chemical inertness, and ease of fabrication. Much new information has been published in recent months on its properties, especially the magnetoresistance. In this paper, data on its electrical properties are collected and correlated, and its figure of merit is determined as a function of purity and field strength for a particular coil configuration.

\section{THE IMPERFECTION RESISTIVITY}

As will appear when the lattice and magnetoresistivities have been discussed, the se latter contribute about 5 to $10 \mathrm{nohm}-\mathrm{cm}$ to the total effective resistivity of aluminum at $20^{\circ} \mathrm{K}$ and $10^{5}$ gauss. It will be advantageous, then, to use a sufficiently well-refined aluminum that its imperfection resistivity is small compared to this. That is, the ratio $\rho_{\mathrm{RT}} / \rho_{4}$ should be at least $10^{3}$, corresponding to purity higher than $99.99 \%$ [ 4 ]. ( $\rho_{\mathrm{RT}}$ signifies the resistivity at room temperature, $2750 \mathrm{nohm}-\mathrm{cm}, \rho_{4}$ that at $4^{\circ} \mathrm{K}$.) Electrolytically-refined metal is commercially available having values of the above ratio as high as about 2500. Much higher ratios are attainable by zone refining, but at such expense as to probably rule out the use of such metal. The practical range of values thus is about 1000 to 2500 at present. 
Equation (2) implies the assumption of Matthiessen's rule

$$
\rho[\mathrm{T}, \mathrm{H}=0]=\rho_{\mathrm{o}}+\rho_{i}
$$

However, large departures occur in the temperature range of interest. These deviations qualitatively fit theoretical models by Kohler and others [5]. If it were our purpose to find a wide-range representation of $\rho[\mathrm{T}, \mathrm{H}=0]$ this could no doubt be accomplished by adding a deviation term to the formulation of Matthiessen's rule. However, since we only wish to represent the resistivity in the vicinity of the optimum temperature, it will be computationally simpler to let $\rho_{i}$ be a function of $\rho_{0}$. The latte $r$ is readily determined via measurement of the ratio of the resistance at room temperature to that at $4^{\circ} \mathrm{K}$ and, in fact, is usually determined in order to characterize the quality of samples.

Measurements by Caron [6] from 14 to $20^{\circ} \mathrm{K}$ of various samples covering a range, $180<\rho_{293} / \rho_{4.2}<6700$, give a clue to a simple procedure. Caron found that the data could be represented by

$$
\rho_{i}=\mathrm{aT}^{3.1 \pm 0.1}
$$

in which the coefficient, a, was an increasing function of $\rho_{0}$.

Maimoni [7] also measured various samples around $20^{\circ} \mathrm{K}$. The range of $\rho_{300} / \rho_{4.2}$ was from 276 to 6630. Logarithmic plots of his lattice resistivities are approximately linear from 15 to $20^{\circ} \mathrm{K}$ with slopes from 2. 5 to 3.1. He also found $\rho_{i}$ to increase with $\rho_{0}$. Maimoni's results can be compared to Caron's for samples having $\rho_{\mathrm{RT}} / \rho_{4}$ of about 2000 and 6700. At these values, Maimoni's resistivities in the vicinity of $20^{\circ} \mathrm{K}$ are roughly $10 \%$ higher than Caron's. 
Evidently both sets of data can be fairly well represented around $20^{\circ} \mathrm{K}$ by

$$
\rho_{i}[T] / \rho_{R T}=a T^{3} ; a=f\left(\rho_{0}\right) .
$$

If $\underline{a}$ is determined by fitting at $20^{\circ} \mathrm{K}$, then the misrepresentation of Caron's function from 15 to $25^{\circ} \mathrm{K}$ due to the exponent being too low by 0.1 is less than $\pm 3 \%$. Similarly, Maimoni's tabular data above $15^{\circ} \mathrm{K}$ are fitted within 6\%. Equation (3) is devoid of theoretical significance and can be expected to apply only for limited ranges of temperature and $\rho_{0}$. However, these include the values of interest for aluminum electromagnets.

The values of a as a function of $\rho_{\mathrm{RT}} / \rho_{4}$ derived from the data of Caron and Maimoni are shown in figure 1. It is suggested that values given by the curve should be used for calculating ideal resistivities by equation (3) [8]. The curve represents the following empirical equation which may be useful for calculations:

$$
\begin{aligned}
10^{8} \mathrm{a} & =2.80+\left(0.17+0.065 \cdot 10^{-3} \mathrm{x}+0.033 \cdot 10^{-6} \mathrm{x}^{2}\right)^{-1} \\
\mathrm{x} & \equiv \rho_{\mathrm{RT}} / \rho_{4} .
\end{aligned}
$$

This method of predicting $\rho_{i}$ is of doubtful value below $x=500$ where the data of figure 1 as well as other data [9] on relatively impure aluminums scatter badly. It apparently is reliable to very high values of $x$. Thus, Montariol and Reich [10] measured the resistivity from $14^{\circ}$ to $20.4^{\circ} \mathrm{K}$ of a zone-refined aluminum with $\mathrm{x}=22,600$. Similarly Aleksandrov and D'Yakov [11] measured a specimen with $\mathrm{x}=29,400$ at $14^{\circ}$ and $20.4^{\circ} \mathrm{K}$. The above authors found the ideal resistivities of these two specimens to go as $T^{3.7}$ and $T^{3.55}$, respectively. If equation (3) is constrained to fit the se data at $20.4^{\circ} \mathrm{K}$, the coefficient $\mathrm{a}$ is found to be $2.79 \times 10^{-8}$ for either specimen. Equation (4) gives values within $2 \%$ of this. 
A few other sources of data bearing on the correlation of figure 1 may be mentioned. Measurements were made from $3^{\circ}$ to $70^{\circ}$ by Lax [16] on a specimen with $x=550$. Below $30^{\circ}$ the resistance varied as $T^{3.24}$. The coefficient obtained by fitting his $20^{\circ}$ datum to the $\mathrm{T}^{3}$ formula falls on the curve of figure 1. Papers by Borovik and coworkers [12, 13, 14] give resistance ratios at $4.2^{\circ}$ and $20.4^{\circ}$ for six specimens with $x$ ranging from 690 to 24,400. These throw no light on the validity of equation (3) in the range around $20^{\circ} \mathrm{K}$; however, values of a can be calculated and are shown in figure 1. Values not shown at $x=11,000$ and 24,400 are $+7 \%$ and $-1 \%$, respectively, different from equation (4). Data by Purcell and Jacobs [15] at $4^{\circ}, 20^{\circ}, 25^{\circ}$, and $30^{\circ} \mathrm{K}$ for two samples are erratic when tested by equation (4) and fail tests of self-consistency based on minimal as sumptions about the behavior expected of $\rho_{i}$. 


\section{SIZE EFFECTS}

\subsection{In Zero Field}

For the conditions of temperature and purity that are of interest here, the mean free path of the electrons may be appreciably long relative to the conductor dimensions. In such a case, the scattering of electrons from the surface will provide an appreciable extra resistance in addition to that attributable to the bulk metal. Aleksandrov [17] and Montariol and Reich [18] have studied this effect by measuring the resistances of round wires of various diameters made from the very pure aluminums mentioned in section 3. For these samples with bulk resistance ratios greater than 20,000, the mean free path at $4^{\circ} \mathrm{K}$ is of the order of $1 \mathrm{~mm}$. By expressing the results in terms of Nordheim's approximate formula [19]

$$
\frac{\rho}{\rho_{\infty}}=1+\frac{\ell}{d}
$$

values of the mean free path $\underline{\ell}$ and the approximately constant product $\rho_{\infty} \ell$ can be derived. Here $\rho_{\infty}$ is the bulk resistivity, and $d$ is the wire diameter. The results are given in table 1. Montariol and Reich also measured three less pure samples at $4.2^{\circ} \mathrm{K}$ for which the values of $\mathrm{x}_{\infty}$ were 12,000, 7000, and 2540. These gave values of $10^{11} \rho_{\infty} l$ of 0.80 , 0.90 , and 1.50, respectively. F $\phi$ rsvoll and Holwech [21] determined size effects in foil specimens made from six grades of aluminum for which $x_{\infty}$ ranged from 1650 to 26,500 . The values obtained for $10^{11} \rho_{\infty} \ell$ varied randomly from 0.53 to 0.88 . Table 1 shows the average value obtained by F $\phi$ rsvoll and Holwech. 
It will be seen that the agreement obtained in these difficult experiments is not very good. ${ }^{1}$ However it would seem that the rounded value, $\rho_{\infty} \ell=1 \times 10^{-11} \mathrm{ohm}-\mathrm{cm}^{2}$, could safely be used for roughly estimating the mean free path of aluminum. Given the mean free path, one can determine the size effect in a given specimen using results of theoretical calculations such as those for films and wires shown in figure 2. (Equation (5) approximates the values shown for round wires within $5 \%$ in $\rho / \rho_{\infty}{ }^{\circ}$ )

For a sample with $x=2000$, the mean free path estimated using $10^{11} \rho_{\infty} \ell=1$ is about $0.04 \mathrm{~mm}$ at $20.4^{\circ} \mathrm{K}$. Thus for magnet conductors of practical dimensions, substantial size effects are likely to occur only in foils or tapes. An example is the tape-wound liquid-hydrogencooled magnet of Purcell and Payne [22] in which the conductor was $0.10 \mathrm{~mm}$. thick; i.e., $\ell / \mathrm{d}$ was 0.4 at $20.4^{\circ} \mathrm{K}$. It will be seen by refer ence to figure 2 that the low-field resistance of this magnet and the residual-resistance ratio reported for a sample of its conductor must have contained a substantial component due to the surface resistance. In fact, as table 2 shows, most of the sources of resistivity data on which we must depend contain errors as large as several percent due to uncorrected size effects. Table 2 shows the maximum size-effect error in each investigation. These were calculated using the $4.2^{\circ} \mathrm{K}$ value of $\rho_{\infty} l$ of Aleksandrov since this agrees fairly well with the values from the anomalous skin effect. Obviously, size effect should always be taken into account in accurate investigations under the conditions of purity and temperature which concern us here.

${ }^{1}$ They are in rough agreement with the values $0.49 \pm .04 \times 10^{-11}$ [20] and $0.40 \times 10^{-11}$ [21] resulting from measurements of the anomalous skin effect. 
Having raised this point it is now necessary to consider if the correlation presented for $\rho_{i}$ should be modified to take the size-effect errors into account. First we may note that $\rho_{i}$ is rather insensitive to size. In fact, it is easy to show that if $\rho_{\infty} \ell$ were constant and the size effect were given by a formula having the form of Nordheim's equation, $\rho_{i}$ would be independent of size. On the other hand, if we adopt the values of $\rho_{\infty} l$ as a function of temperature found by Aleksandrov, then $\rho_{i}$ from Maimoni's data increases slightly more rapidly with temperature, but the increase in the exponent $\mathrm{n}$ is only 0.1 . The values of $\rho_{i}$ at $20^{\circ} \mathrm{K}$ are lower but are within $5 \%$ of the uncorrected values.

It has not seemed worthwhile to correct the recommended ideal resistivities of section 3 for the following reasons:

(1) In view of the disagreement shown in table 1, our knowledge of the parameter $\rho_{\infty} l$ is inaccurate.

(2) The ideal resistivity is a minor part of the total resistivity in the conductor of a high-intensity magnet as will appear in section 6 . Hence an uncertainty in it of a few percent can be neglected.

(3) Maimoni used specimens of two configurations (table 2) for which the size-effect corrections are appreciably different. Application of the corrections does not smooth the correlation shown in figure 1. Hence other sources of scatter outweigh the size effect in his investigation.

(4) Application of the correction does not reduce the discrepancies between the $\rho_{i}$ from Caron and those from Maimoni; in fact, for the specimens with $x$ near 6700, it appreciably worsens the agreement. Thus this discrepancy must be due to other causes that are much more significant than size effects. 
When a sample thin enough to show the zero-field size effect is placed in an increasing magnetic field, two effects operate simultaneously:

(1) The resistance rises with magnetic-field intensity according to the bulk magnetoresistance effect (see next section).

(2) The radius $(r=m v c / e H)$ of the orbital motion of the conduction electrons in the magnetic field decreases, and consequently they collide less often with the surface. The exact behavior of the surface resistance depends on the relative orientations of field, current, and specimen [19]. However, there is only one case among practical magnet configurations where the galvanomagnetic size effect is likely to be observed, i.e. the flat-wound foil coil. Here the field is in the plane of the foil but perpendicular to the current. In the field region where the orbital radius is comparable to the sample thickness, the surface component of the resistance falls rapidly with increasing field, becoming negligible when the orbital radius has become much smaller than the sample thickness.

Combination of the two effects above may give $\mathrm{R}-\mathrm{H}$ curves of varied shapes. If the size effect is initially strong a minimum may occur, after which the resistance again rises due to the bulk magnetoresistance alone $[23,24]$.

The available knowledge of size effects in magnetic fields is insufficient for accurate prediction [19, 25]. However, this does not matter much in designing high-field magnets because the conductor size effect, if present at all, will generally have vanished by the time the field has reached a few thousand oersteds. This is evident from the radius of the electron orbits in aluminum which has shrunk to the order of $0.01 \mathrm{~mm}$. at 10 koe [23]. Since we are concerned with much larger fields than this, and the magnet conductor is not likely to be thinner than $0.1 \mathrm{~mm}$., the size effect under such conditions will have vanished relative to the bulk magnetoresistance. 


\section{MAGNETORESIST ANCE}

The sources of data on the magnetoresistance of aluminum are listed in table 3. The transverse magnetoresistance is of primary interest, inasmuch as this is the effect occurring in simple solenoids. The correlation of the data was examined by placing them on a plot of $\rho_{\mathrm{H}} / \rho$ vs. $\mathrm{H}_{*} \equiv \mathrm{H} \rho_{\mathrm{RT}} / \rho$ according to Kohler's rule, $\rho_{\mathrm{H}} / \rho=\mathrm{f}(\mathrm{H} / \rho)$. Here $\rho$ and $\rho_{\mathrm{RT}}$ are resistivities in zero field, and $\rho_{\mathrm{H}}$ is the increase in resistivity due to the field $\mathrm{H}$, measured at the same temperature as $\rho$. Superficially the data appear to follow the theoretical form [26]

$$
\frac{\rho_{\mathrm{H}}}{\rho}=\frac{\mathrm{H}_{*}^{2}}{\mathrm{~A}+\mathrm{BH}_{*}^{2}}
$$

i. e., an initial $\mathrm{H}_{*}^{2}$ dependence followed by saturation. However, closer inspection reveals two significant differences:

(1) The "saturation" region at high $\mathrm{H}_{*}$ is actually $r$ ather accurately linear, though the slope is small $[27,28,29,30]$. By inverting the conductivity tensor, more general theoretical formulas can be obtained [30] which contain the desired pseudo-linear region following the initial quadratic region. At still higher values of $\mathrm{H}_{*}$, the se predict either saturation or a second quadratic region, neither of which phenomena have been definitely demonstrated to occur. Consequently we choose to obtain a fit to the linear region by multiplying the numerator above by $\left(1+\mathrm{CH}_{*}\right)$, thus obtaining a simpler formula which, however, may not safely be used for extrapolation to larger $\mathrm{H}_{*}$. 
The failure to truly saturate is apparently an anomaly. For a given direction of magnetic field in a crystal, the magnetoresistance at very high fields must saturate unless there are extended electron trajectories made possible by contact of the Fermi surface with the Brillouin zone boundary, in which case the behavior would be as $\mathrm{H}^{2}$ at all fields. In a random polycrystal the net behavior corresponding to suitable averaging of saturating and quadratic behavior may turn out to be linearity with $\mathrm{H}[19]$, e.g., copper. However, there are two reasons why this kind of explanation does not seem to apply to aluminum [28, 30]. First, extensive measurements with single crystals show the same $\rho_{\mathrm{H}} / \rho$ vs. H behavior at all orientations, i.e., essentially the curve shape of figure 3. Second, no sharp anisotropy of $\rho_{H} / \rho$ at constant $H$ is found, such as that found with e.g. copper and gold.

(2) If values of $A, B$, and $C$ are adopted so as to represent the limiting behaviors at small and large $H_{*}$, then the fit is bad in the transition zone, such that the calculated $\rho_{\mathrm{H}} / \rho$ is nearly twice too large at about $\mathrm{H}_{*}=2$. Analysis suggests addition of a term in $\mathrm{H}_{*}$ in the denominator.

With these modifications we have a formula, unfortunately empirical, but nevertheless helpful in computer calculations and as a base line from which to examine the experimental data. The chosen function is as follows where $\mathrm{H}_{*}$ is in megoersteds.

$$
\frac{\rho_{\mathrm{H}}}{\rho}=\frac{\mathrm{H}_{*}^{2}\left(1+0.00177 \mathrm{H}_{*}\right)}{1.8+1.6 \mathrm{H}_{*}+0.53 \mathrm{H}_{*}^{2}} .
$$


It is displayed in figure 3. The percentage deviations from it of the experimental data are shown in figures $4 \mathrm{a}, 4 \mathrm{~b}$, and $4 \mathrm{c}$. In most cases the "experimental" data were read from smooth curves in the original publications; in such cases the deviation curves are also smooth. In a few cases ( $\mathrm{P}-\mathrm{J}$ and $\mathrm{H}-\mathrm{A}$ in figure $4 \mathrm{c}$ ) the original data points were used; here the deviation curves are made up of straight segments. The precision with which the original data were expressed is always worst at the lowest field. In some cases (identified by bars) the data could be recovered with only one significant figure. The height of the bar indicates only the precision of the published value of $\rho_{\mathrm{H}} / \rho$. In most of the investigations no basis is provided for estimating the accuracy. Following are some comments about specific investigations.

Kapitza. These remarkable pioneering measurements are mainly of historical interest. The values of $\rho_{\mathrm{RT}} / \rho_{4}$ in table 3 were estimated from his values of $\rho_{\mathrm{RT}} / \rho_{\mathrm{N} 2}$, but are uncertain due to ambiguities as to the value of the temperature.

De Haas and Van Alphen. These are the only data in the $\mathrm{H}_{*}^{2}$ region. Justi and Scheffers. These data were presented as a plot of $\rho_{H}$ vs. $H$. In order to place them on a Kohler plot it was necessary to estimate the zero-field resistivity from $4^{\circ}$ to $78^{\circ}$. These estimates, as well as the estimate of $\mathrm{x}$ in table 3 , were based on values given for the ratios $\rho_{20} / \rho_{273}$ and $\rho_{14} / \rho_{273^{\circ}}$ Later Foroud, Justi, and Kramer [31] published a reduced Kohler plot based on the data of Justi and Scheffers but, curiously, using only the data at $4^{\circ}$ and $64^{\circ} \mathrm{K}$. This reduced Kohler plot used $\rho_{\theta}$ rather than $\rho_{\mathrm{RT}}$ in $\mathrm{H}_{*}$; the assumed values of $\theta$ and $\rho_{\theta}$ were not given. Thomas and Mendoza. These data, lying in the range $\mathrm{H}_{*}=0.1$ to 0.5 moe, are an order of magnitude higher than all others and are given no weight. 
Lüthi and Olsen. This investigation showed the usual behavior up to about $\mathrm{H}_{*}=20$ moe followed by an anomalous rapid rise in $\rho_{\mathrm{H}} / \rho$. Later Lüthi [32] attributed this to eddy-current heating produced by the pulsed magnetic field. Borovik and Volotskaya [13] suggested that misalignment of the potential contacts with the current direction could have produced this result by including a component of the Hall field which, for aluminum, is large relative to the electric field in the current direction.

Lüthi 1960. The data had to be taken from a reduced Kohler plot for which $\theta$ was stated to be $410^{\circ} \mathrm{K}$, but $\rho_{\theta}$ was not furnished. To reduce to the basis of figure 4 , it has been assumed that $\rho_{410} / \rho_{273}=1.62$.

Purcell and Jacobs. As was mentioned in section 3, the zero-field data of Purcell and Jacobs are erratic. The scatter of their curves in figure 4 is partly attributable to this.

Babiskin and Siebenmann. Four specimens from a common stock were used; two had different degrees of cold-work and the other two were given different anneals. Figure $4 a$ shows only the specimen (III) that was most completely annealed and that had the highest ratio, $x$. It also showed about average behavior on a Kohler plot of the data for all four specimens. The results indicated no ordering by resistance ratio, and the extremes were provided by the two cold-worked specimens. The results for all specimens lay within $\pm 10 \%$ of specimen III.

Borovik, Volotskaya, and Fogel'. In addition to the data shown in figure $4 \mathrm{~b}$ these authors give curves in the same range of $\mathrm{H}_{*}$ for three high-purity crystals at $20^{\circ} \mathrm{K}$ which show $\rho_{\mathrm{H}} / \rho$ rising to maximum values from 4 to over 6 . These results indicate that Kohler's rule is not even approximately valid. However, the specimen purities for which these results were found $(x=6,875$ to 24,400$)$ fall outside the range that is presently of practical importance for electromagnets. 


\section{1 Discussion}

The region of greatest interest in connection with electromagnets is roughly $\mathrm{H}=10,000$ to 200,000 oe and $\mathrm{x}=1000$ to 2500 , or $\mathrm{H}_{*}=10$ to 500 moe. The curves of figure 4 show no discernable ordering with the various experimental parameters, except that the data at temperatures in the liquid hydrogen range $\left(14-30^{\circ}\right)$ tend to be higher than those at helium temperatures $\left(1-4^{\circ}\right)$. The relative crudeness of the correlation shown indicates that the experimental parameters are inadequately controlled and, indeed, may not yet be completely identified. Some possible sources of variation will now be discussed.

It was shown in the preceding section that many of the zero-field data contain appreciable errors due to size effect. The magnetoresistance itself is probably unaffected at the large values of $\mathrm{H}_{*}$ which are of practical concern. However the correlation via Kohler's rule involves the zero-field resistivity. Because of the near-saturating behavior at high $\mathrm{H}_{*}$, the effect of correcting for surface scattering would be to raise the curve of $\rho_{\mathrm{H}} / \rho$ in this region. However, it is apparent that there is little or no correlation between the discrepancies of figure 4 and the sizeeffect errors indicated in table 2.

The magnetoresistance is generally anisotropic. This could produce variations even in data obtained with polycrystalline specimens if there were preferred orientation of the crystallites varying from specimen to specimen. However, the anistropy of magnetoresistance in aluminum is not very great. Justi and Scheffers [33] first reported that the anisotropy was small but were unable to give quantitative details due to experimental difficulties. Lüthi [34] gave polar diagrams for the variation of transverse magnetoresistance with rotation of the field vector for currents 
in the [100] and [110] directions in a rather impure crystal (see table 3). The total range of variation of $\rho_{H} / \rho$ at 10 koe was only $18 \%$. A more detailed study was made by Stark and Eck [28] using crystals of high purity (see table 3). Polar diagrams were obtained for currents in the [100], [110], and [111] directions and showed no marked anisotropy. Curves of $\rho_{H} / \rho$ vs. H for various field directions and [110] current direction - the case showing greatest anisotropy - for a specimen with $\mathrm{x}=3800$ showed the same form as figure 3. At 16.7 koe $\left(\mathrm{H}_{*}=64 \mathrm{moe}\right)$ they lay within $\pm 25 \%$ of the value in figure 3. Balcombe's work [30] was even more elaboràte. Again the curves of $\rho_{\mathrm{H}} / \rho$ vs. $\mathrm{H}$ had the usual shape regardless of orientation, and there were no sharp variations in $\rho_{\mathrm{H}} / \rho$ with changing orientation at constant $H$. Kohler's rule was found to hold provided the same orientation was maintained. At $\mathrm{H}_{*}=35$ where Balcombe's data are most extensive, the extrema of $\rho_{\mathrm{H}} / \rho$ are $+12 \%$ to $-28 \%$ from the value in figure 3. Similar but less extensive measurements by Volotskaya [35] follow this same pattern, except that a more steeply rising curve was found for just one sample at a particular orientation. This freakish result, if it is not due to an experimental error, could conceivably indicate the existence of the looked-for open electron orbits, though in such a small part of the Fermi surface as to be found only accidentally with present crystal orienting techniques. Finally, Borovik, Volotskaya, and Fogel' [14] have reported a "strong" anisotropy and an unusual field dependence at $4^{\circ}$ for specimens with $\rho_{273} / \rho_{4}>10,000$, but they gave no details, promising a later publication. For the same specimens at $20^{\circ} \mathrm{K}$, the anisotropy did not exceed $\pm 15 \%$. From all of these results it is clear that preferred orientations of crystallites in polycrystalline samples may result in appreciable, though not major, variations in the magnetoresistance at liquid hydrogen temperatures. It seems unlikely that such variations could exceed $10 \%$. Nevertheless, accurate measurements on polycrystalline samples ought in future to be accompanied by $\mathrm{x}-\mathrm{ray}$ examination for preferred orientation in order to be as meaningful as possible. 
Errors due to inclusion of a component of the Hall potential have been mentioned (discussion above of Lüthi and Olsen's results). Borovik and Volotskaya [13] noted such effects. Stark and Eck [28], Babiskin and Siebenmann [29], and Balcombe [30] took pains to eliminate this effect by field reversal.

Nonaxial current flow in the region of the potential contacts must be guarded against [36], as substantial effects may result, especially with short specimens. Babiskin and Siebenmann [29] found that spurious values of $\rho_{H} / \rho$ as large as 10 due to such effects could be obtained.

Measurements in pulsed fields are susceptible to further sources of error such as induced voltages, eddy-current heating, skin effect, and motion under reaction forces. These have been discussed by Kapitza [37] and Lüthi [32].

Finally some mention should be made of the longitudinal magnetoresistance, inasmuch as this effect will play a role in so-called "force-free" coils for producing very high fields. Sources of data are indicated in table 3, of whom Lüthi [32] provides the only extensive results. His data follow a "saturating" Kohler plot with the values of $\rho_{\mathrm{H}} / \rho$ above the knee of the curve amounting to $40 \%$ of the transverse case. The other sources indicate values of the ratio longitudinal $\div$ transverse of 30 to $60 \%$.

\section{THE FIGURE OF MERIT}

We have now provided a basis for calculating the figure of merit of aluminum electromagnets. Provided the resistance ratio, $x$, of the conductor has been determined, then equations(2), (3), (4), and (6)can be used to calculate the resistivity and equation 1 the figure of merit. The magnetoresistance must be averaged to take into account the variation of field within the coil. Techniques for calculating the field distribution in coils are well established [38]. 
As an example we will calculate $\phi$ for a particular coil. We will adopt a long rectangular solenoid, i.e., neglecting fringing. The current density is assumed constant throughout the coil. The induction in the coil is assumed to vary linearly from $\mathrm{H}_{0}$ at the inside radius, $r_{1}$, to zero at the outside radius, $r_{2}$. Then, using the reduced coordinates, $a \equiv r_{2} / r_{1}$ and $\mathrm{y} \equiv \mathrm{r} / \mathrm{r}_{1}$, the volume-average magnetoresistance is given by

$$
\bar{\rho}_{\mathrm{H}}=\frac{2}{a^{2}-1} \int_{1}^{a} \mathrm{y} \rho_{\mathrm{H}} \mathrm{dy}
$$

where $\rho_{\mathrm{H}}$ is furnished by equation 6. A value of 3 was adopted for $a$. This average magnetoresistance is then inserted for $\rho_{\mathrm{H}}$ in equation 2. The calculation was carried out for $\mathrm{H}_{0}=50,100$, and $200 \mathrm{koe}$ and for seven values of $\mathrm{x}$ from 1000 to $\infty$. The results are shown in figure 5 .

As we have seen, the equations used are applicable only within certain limits. The se are as follows: The validity of equation 3 for the lattice resistivity is established only for the region $14^{\circ}$ to $20^{\circ} \mathrm{K}$, though it may be sufficiently accurate over a wider range; equation 6 for the magnetoresistance is limited to $\mathrm{H}_{*} \approx 200$ moe and, in view of the data of Borovik, Volotskaya, and Fogel', to $x \approx 2500$ in the liquid hydrogen region. The curves of $\phi$ are dashed where these limits have been transgressed.

Figure 6 shows the components of the resistivity at the minima in $\phi$ for $\mathrm{H}_{0}=100 \mathrm{koe}$. The corresponding curves for $\mathrm{H}_{\mathrm{o}}=50$ and $200 \mathrm{koe}$ are quite similar. 


\section{DISCUSSION}

Figure 5 suggests that the conductor metal should be purified to as high a degree as possible, or at least to some maximum degree that would be dictated by balancing the cost of refining against the anticipated operating costs. However this conclusion will not be valid if the abnormally high magnetoresistances found at $20^{\circ} \mathrm{K}$ by Borovik et al. [14] for zone-refined samples prove to be representative. Then there will be an optimum purity corresponding to a residual-resistance ratio lying somewhere between 2000 and 7000 . For the present we cannot safely predict beyond $x=2000$ because of Borovik's findings; and for this or lower values of $\mathrm{x}$ we cannot safely predict beyond $\mathrm{H}_{\mathrm{o}}=100 \mathrm{koe}$ because this would take us into a region of $\mathrm{H}_{*}$ where data are unavailable and theoretical predictions are not firm. However it is clear that $\phi$ can be lowered at least to 0.20 at $\mathrm{H}_{\mathrm{o}}=100 \mathrm{koe}$, a very valuable gain for large magnets.

The areas in which additional data are needed are now rather clearly defined.

1) More reliable and extensive magnetoresistance data are needed in the region $14-20^{\circ} \mathrm{K}$.

2) The measurements of Borovik at $20^{\circ}$ and for $x>7000$ should be verified and extended to samples for which $\mathrm{x}=2000$ to 7000 .

3) The Kohler plot for aluminum should be extended beyond $\mathrm{H}_{*}=200$ moe by high field measurements on very pure zone-refined samples. For the best sample yet produced, $x$ was nearly 30,000 [11]. Steady magnetic fields as high as 100 koe and pulsed fields up to several hundred thousand oersteds are available in a number of laboratories [38]. Thus values of $\mathrm{H}_{*}$ as high as 3000 moe (steady) and $\sim 10^{4}$ moe (pulsed) should be attainable at liquid helium temperatures with present experimental techniques and materials. 


\section{APPENDIX. EFFECTS OF PLASTIC DEFORMATION}

The yield strength of high-purity aluminum is quite low. Thus, for example, the foil with $x=1370$ used in the magnet of Purcell and Payne [22] had a yield strength of $3000 \mathrm{psi}$ at room temperature; a zone-refined wire of $99.999 \%$ purity showed a yield strength of about 2000 psi at $78^{\circ} \mathrm{K}$ [39]. Pure single crystals may yield even more readily in the directions of easy glide; for example, Wintenberger [40] has reported a roomtemperature yield strength of about 200 psi for such a sample. These yield strengths would be expected to increase only moderately on cooling to $20^{\circ} \mathrm{K}$. Thus strength is an important consideration in designing cryogenic aluminum magnets. The mechanical designing of magnets is beyond the scope of this paper. However the question may arise as to what resistivity changes might be expected should plastic deformation accidentally occur during operation of an aluminum magnet. Some data are available that bear on this question.

Pistorius [39] measured the resistivity at $78^{\circ} \mathrm{K}$ as a function of tensile strain at that temperature for wires nominally of $99.999 \%$ purity. He found an initial rate of change of $0.2-0.4 \mathrm{nohm}-\mathrm{cm}$ per $1 \%$ strain for annealed wires. Wintenberger [40] obtained changes of about 0.1 nohm$\mathrm{cm}$ (measured at $20^{\circ} \mathrm{K}$ ) per $1 \%$ tensile strain at room temperature for specimens of 99.98 to $99.999 \%$ purity.

Regarding recovery after straining, Mlle. Frois [41] found that the effects of large strains at $20^{\circ} \mathrm{K}$ were completely recovered below room temperature. She used a zone-refined sample with about $5 \mathrm{ppm}$ impurities rolled to a reduction in thickness of $96 \%$. The resistivity at $20^{\circ} \mathrm{K}$ of the annealed sample before rolling was 0.9 nohm-cm. From this datum and the correlation of section 3, the residual-resistance ratio is estimated to have been 11,000. Most of the recovery occurred at about $175^{\circ} \mathrm{K}$. No 
data are available on recovery after small strains at $20^{\circ} \mathrm{K}$. Generally higher temperatures are required for recovery from small strains. Wintenberger [40] found that recovery from small strains imposed at room temperature was not completed at room temperature. It would be of some practical value to study the recovery from small deformations at $20^{\circ} \mathrm{K}$ for samples of intermediate purity (i.e., $\mathrm{x}=1.000$ to 2500 ).

\section{ADDENDUM}

Since this note was written, a paper by Försvoll and Holwech [47] has appeared which gives extensive data on galvanomagnetic size effects. Polycrystalline strip samples were used with values of $x$ ranging from 200 to 26400 and $\ell / d$ as large as 60 . Transverse fields up to $13 \mathrm{koe}$ were used at $4.2^{\circ} \mathrm{K}$. The angle between the field vector and the plane of the specimen was varied. The results were qualitatively of the form predicted by theory but differed quantitatively in several respects. Thus, for the case described in section 4.2 , the $\rho-H$ curves had the predicted shape but did not coalesce as expected to the bulk resistivity at high fields.

Estimates of the bulk magnetoresistance were made by applying a somewhat arbitrary correction for the galvanomagnetic size effect. The results provide an extension of the known range since a maximum value of $\mathrm{H} *$ of 280 moe was reached. At the higher values of $\mathrm{H} *$ the results conform to those of Lüthi [32] but are substantially lower than the curve of equation 6 and figure 3. The maximum value attained for $\rho_{\mathrm{H}} / \rho$ was 1. 6 whereas equation 6 predicts 2.8 . The magnetoresistance was still rising slowly at the maximum value of $\mathrm{H} *$ that was reached. 
Table 1. Size-Effect Parameters

Temperature

$\rho_{\infty} \ell, \mathrm{ohm}-\mathrm{cm}^{2}$

Aleksandrov[17]

Montariol

F $\phi$ rsvoll

${ }^{\circ} \mathrm{K}$ \& Reich[18]*

\& Holwech[21]

4.2

$0.55 \times 10^{-11}$

14.

$0.77 \times 10^{-11}$

20.4

$0.935 \times 10^{-11}$

1. $00 \times 10^{-11}$

$0.70 \times 10^{-11}$

1. $40 \times 10^{-11}$

* Sample ZF 1, $x=22,600$ 


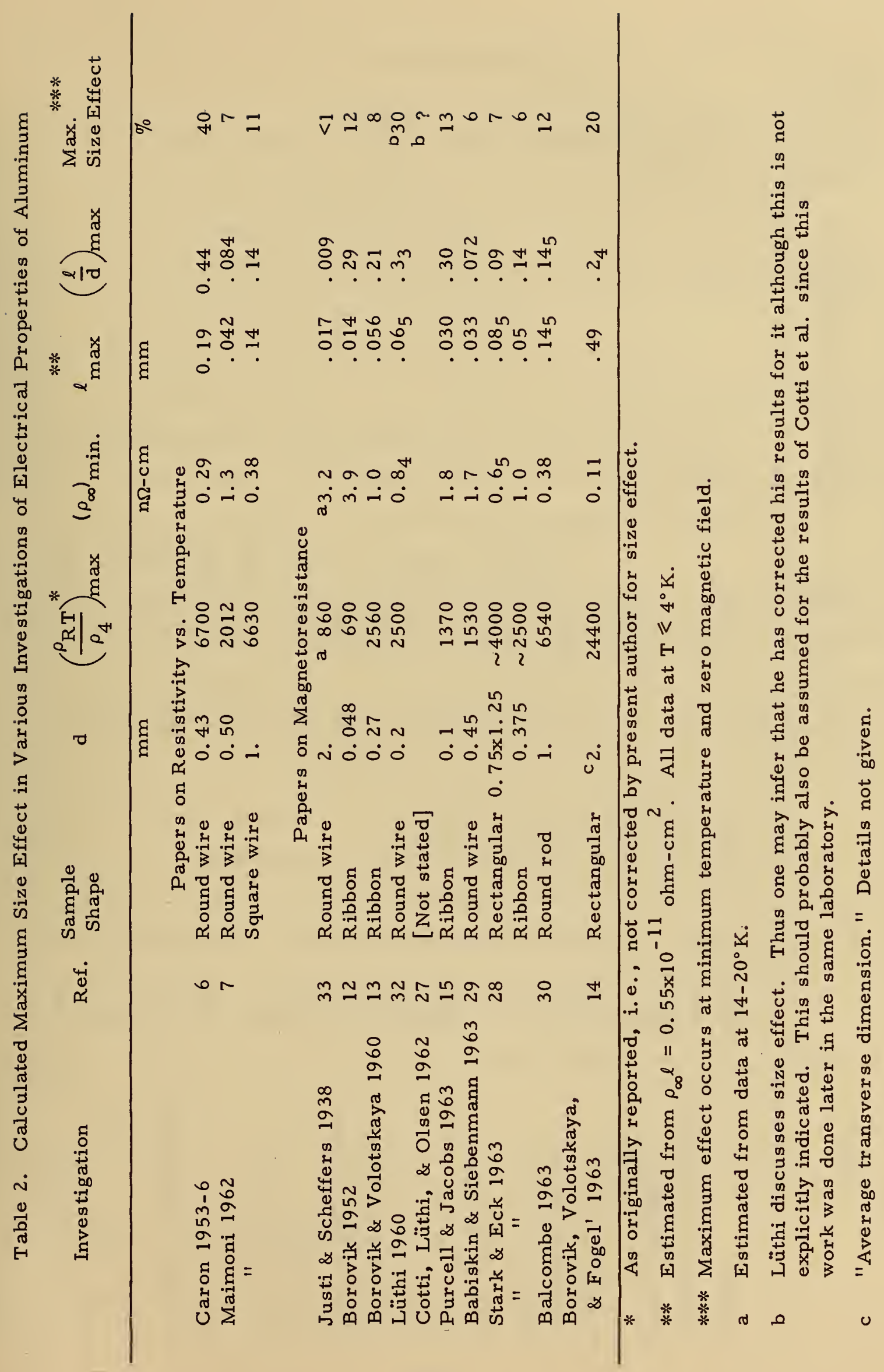


\%

究望

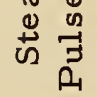

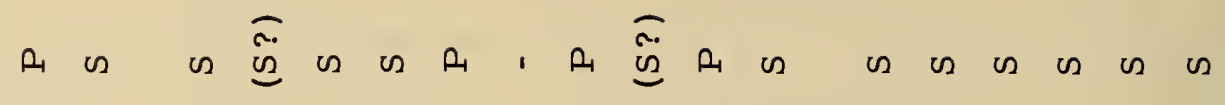

范莡

$\therefore$

की

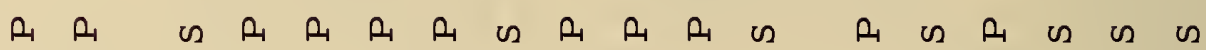

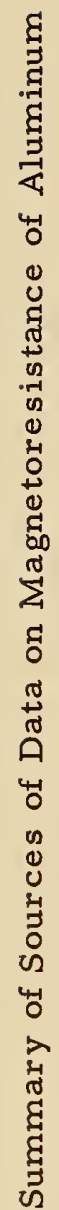

ค.

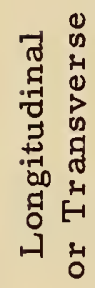

象|

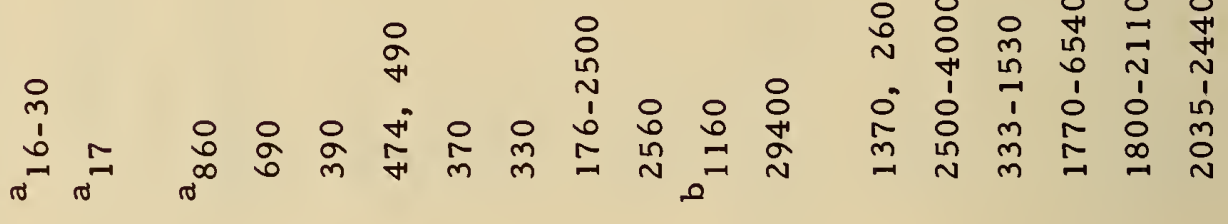

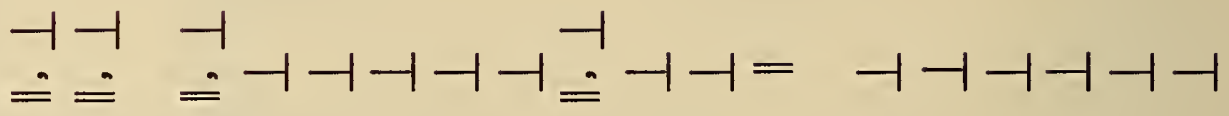

(1)

x

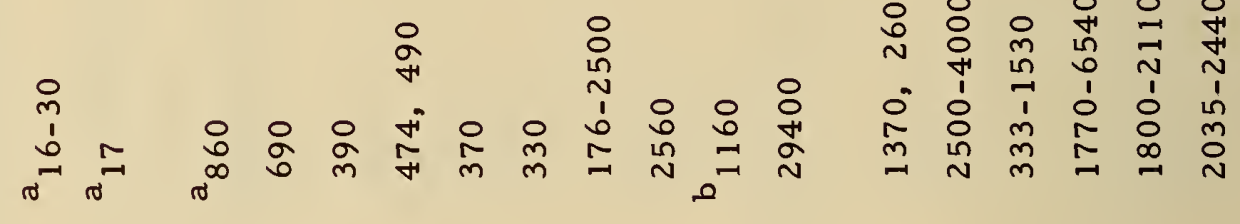

帘

: ก

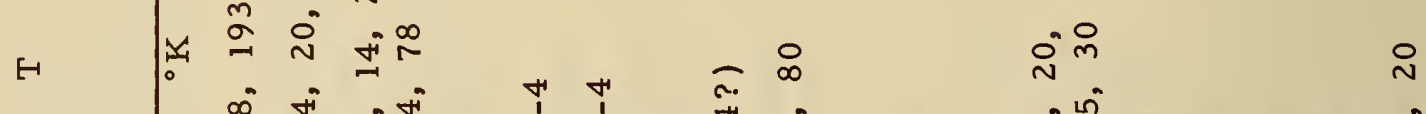

$\infty_{\infty}^{\infty}$ 开

峁

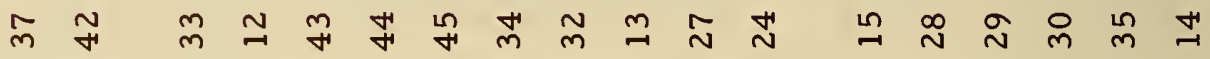

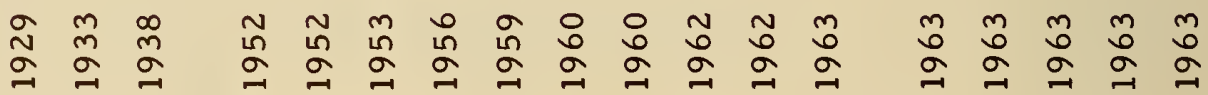

$\stackrel{0}{\stackrel{0}{\pi}}$

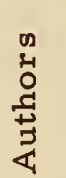

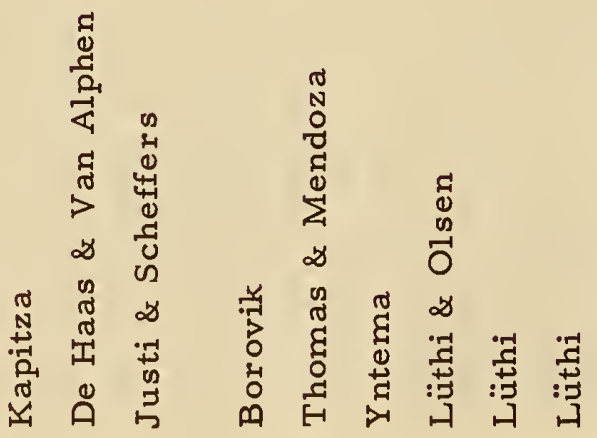

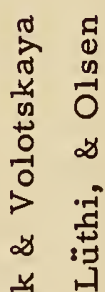

趂 


\section{REFERENCES}

[1] C. E. Taylor and R. F. Post, High Magnetic Fields, H. Kolm, B.

Lax, F. Bitter, and R. Mills, eds., The MIT Press and John Wiley \& Sons, Inc. p. 101 (1962).

[2] R. F. Post and C. E. Taylor, Adv. in Cryogenic Engineering $\underline{5}$, 13 (1959); Plenum Press, New York.

[3] D. B. Chelton and D. Mann, unpublished studies.

[4] T. G. Pearson and H. W. L. Phillips, Met. Revs. 2, 305 (1957).

[5] P. Alley and B. Serin, Phys. Rev. 116, 334 (1959).

[6] M. Caron, Bull. Inst. Intern. du Froid, Annexe 1956-2, p. 51;

Compt. Rend. 236, 1169 (1953); ibid. 238, 686 (1954).

[7] A. Maimoni, Cryogenics 2, 217 (1962).

[8] The subscript RT for "room temperature" is here applied loosely to the region $293^{\circ}-300^{\circ} \mathrm{K}$. For computational purposes it is defined by the relation $\rho_{\mathrm{RT}}=1.10 \rho_{273^{\circ}}$ Caron's ratios based on $293^{\circ}$ and Maimoni's based on $300^{\circ}$ were not adjusted to a common temperature since their agreement would not have been improved thereby. Resistance ratios can be converted to resistivities using $\rho_{\mathrm{RT}}=2.75 \mu \mathrm{ohm}-\mathrm{cm}$. Adjustments for small changes in the reference temperature for ratios can be made using the coefficient $\frac{1}{\rho} \frac{\mathrm{d} \rho}{\mathrm{dT}}=0.0043$. The above data are based on the compilation of resistivities in the vicinity of room temperature in LandoltBörnstein tables, Vol. II, Part 6-I, p. 3 (1959).

[9] H. A. Boorse and H. Niewodniczanski, Proc. Roy. Soc. London A153, 463 (1936).

[10] F. Montariol and R. Reich, Compt. Rend. 254, 3535 (1962).

[11] B. N. Aleksandrov and I. G. D'Yakov, Soviet Phys. JETP 16, 603 (1963). [Original in JETP $\underline{43}, 852$ (1962). ] 
[12] E. S. Borovik, JETP 23, 83 (1952).

[13] E. S. Borovik and V. G. Volotskaya, Soviet Physics JETP 11 , 189 (1960). [Original in JETP 38, 261 (1960). ]

[14] E. S. Borovik, V. G. Volotskaya, and N. Ya. Fogel', Soviet Physics JETP 18,34 (1964). [Original in JETP $\underline{45}, 46$ (1963). ]

[15] J. R. Purcell and R. B. Jacobs, Cryogenics 3, 109 (1963).

[16] E. Lax, Phys. Rev. 115, 1591 (1959).

[17] B. N. Aleksandrov, Soviet Phys. JETP 16, 286 (1963). [Original in JETP $\underline{43}, 399$ (1962). ]

[18] F. Montariol and R. Reich, Compt. Rend. 254, 3357 (1962).

[19] J. L. Olsen, Electron Transport in Metals, Chapter 4, Interscience Publishers (1962).

[20] R. G. Chambers, Proc. Roy. Soc. London A215, 481 (1952).

[21] K. Førsvoll and I. Holwech, J. Appl Phys. 34, 2230 (1963).

[22] J. R. Purcell and E. G. Payne, Rev. Sci. Instr. 34, 893 (1963).

[23] K. F prsvoll and I. Holwech, Physics Letters 3, 66 (1962). See also T. Amundsen and T. Olsen, ibid. $\underline{4}, 304$ (1963) for an unpublished result by F $\phi$ rsvoll and Holwech.

[24] B. N. Aleksandrov, Soviet Physics JETP 16, 871 (1963).

[Original in JETP $\underline{43}, 1231$ (1962).]

[25] E. H. Sondheimer, Adv. in Phys. 1, 1 (1952).

[26] J.-P. Jan, Solid State Physics, F. Seitz and D. Turnbull, eds., Academic Press, New York 5, 24 (1957).

[27] P. Cotti, B. Lüthi, and J. L. Olsen, High Magnetic Fields, H. Kolm, B. Lax, F. Bitter, and R. Mills, eds., The MIT Press and John Wiley \& Sons, Inc., p. 526 (1962).

[28] R. W. Stark and T. G. Eck, Air Force Office of Scientific Research Report AFOSR-951 (Jan. 1963).

[29] J. Babiskin and P. G. Siebenmann, Naval Research Laboratory Report 5949 (May 9, 1963). 
[30] R. J. Balcombe, Proc. Roy. Soc. London A275, 113 (1963).

[31] A. Foroud, E. Justi, and J. Kramer, Phys. Z. 41, 113 (1940).

[32] B. Lüthi, Helv. Phys. Acta 33, 161 (1960).

[33] E. Justi and H. Scheffers, Phys, Z. 39, 105 (1938).

[34] B. Lüthi, Helv. Phys. Acta 32, 470 (1959).

[35] V. G. Volotskaya, Soviet Physics JETP 17, 56 (1963). [Original in JETP 44, 80 (1963). ]

[36] N. E. Alekseevskii, N. B. Brandt, and T. I. Kostina, Soviet Phys. JETP 7, 924 (1958). [Original in JETP 34, 1339 (1958).]

[37] P. Kapitza, Proc. Roy. Soc. London A123, 314 (1929).

[38] High Magnetic Fields, H. Kolm, B. Lax, F. Bitter, and R. Mills, eds., The MIT Press and John Wiley \& Sons, Inc. (1962).

[39] C. A. Pistorius, Physica 27, 149 (1961).

[40] M. Wintenberger, Acta Met. ㄱ, 549 (1959).

[41] C. Frois, Compt. Rend. 256, 2166 (1963).

[42] W. J. De Haas and P. M. Van Alphen, Leiden Comm. No. 225a (1933).

[43] J. G. Thomas and E. Mendoza, Phil. Mag. 43, 900 (1952).

[44] G. B. Yntema, Phys. Rev. 91, 1388 (1953).

[45] B. Lüthi and J. L. Olsen, Nuovo Cimento 3, 840 (1956).

[46] D. K. C. MacDonald and K. Sarginson, Proc. Roy. Soc. London A.203, 223 (1950).

[47] K. Försvoll and I. Holwech, Phil. Mag. 9, 435 (1964). 


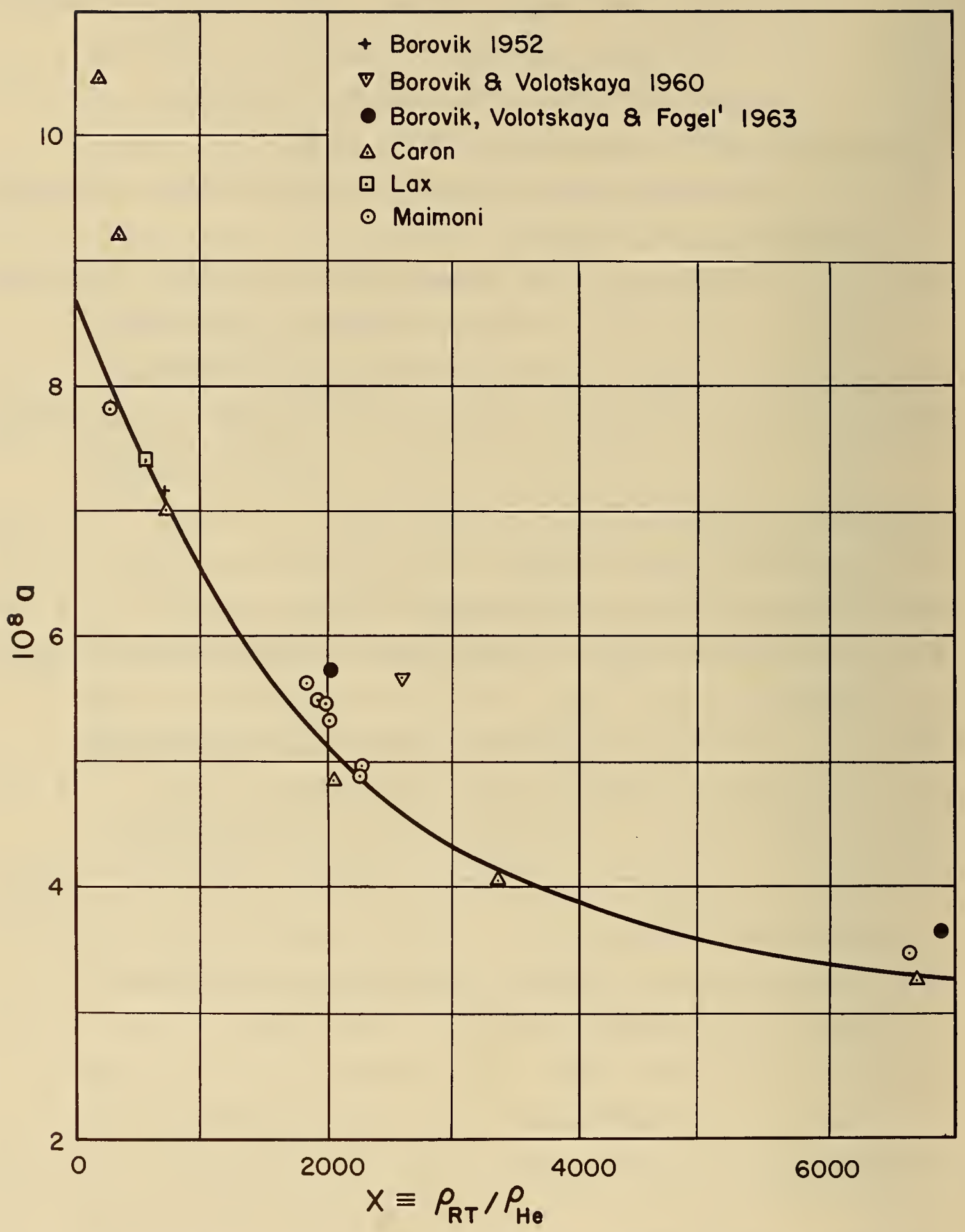

Fig. 1 Coefficient a of equation (3) as determined by fitting the experimental data at $20^{\circ} \mathrm{K}$. The curve represents equation (4). 


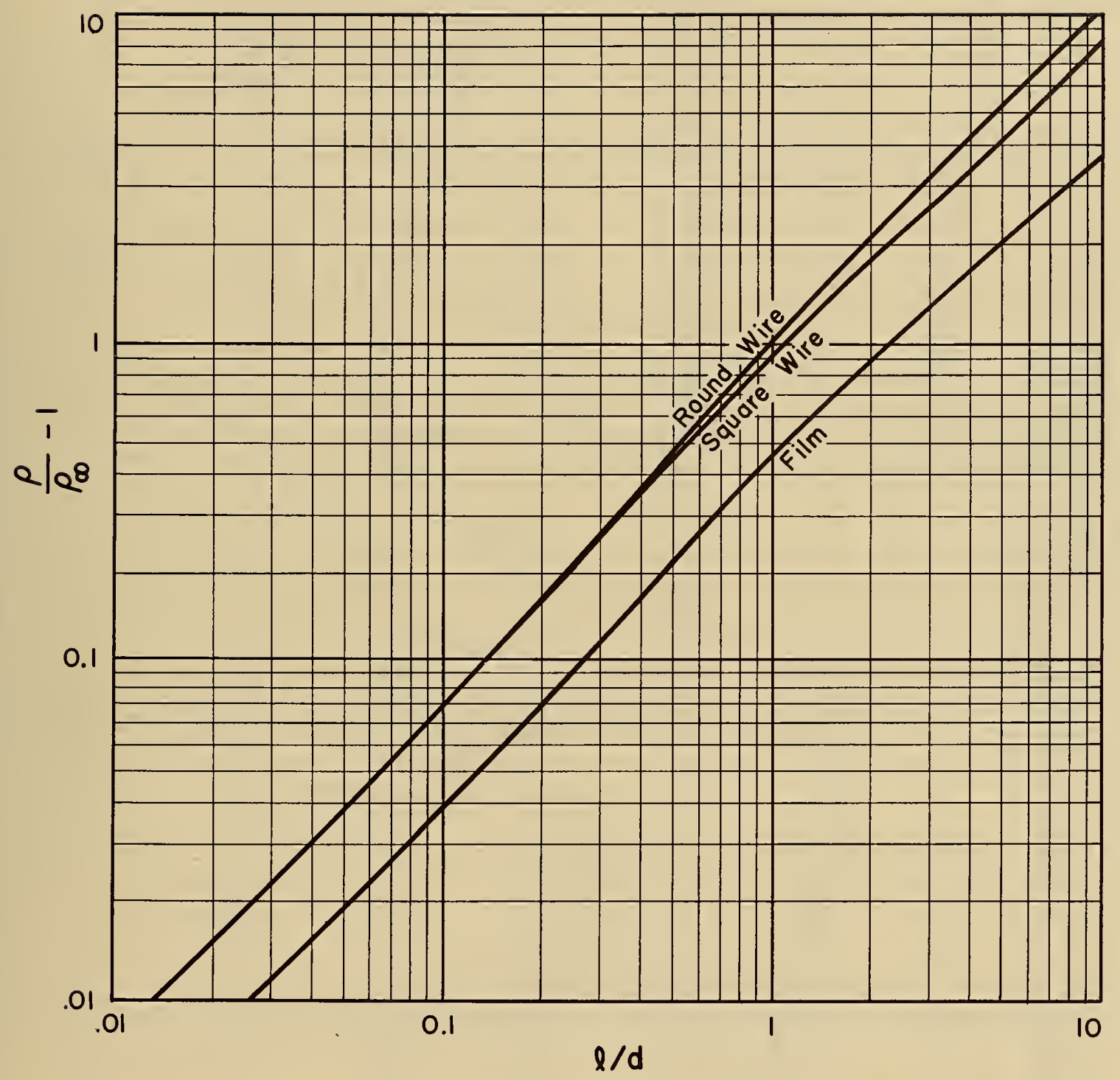

Fig. 2 Size effect by theoretical calculation. $\rho / \rho_{\infty}$ is the ratio of thin to infinitely thick specimens, $\ell$ is mean free path, $d$ is diameter (if round), width (if square), or thickness (if a film). Data for round wire and for film are from Sondheimer [25]; those for square wire are from MacDonald and Sarginson [46]. Nordheim's formula, equation (5), is the diagonal line from lower left to upper right (not shown). 


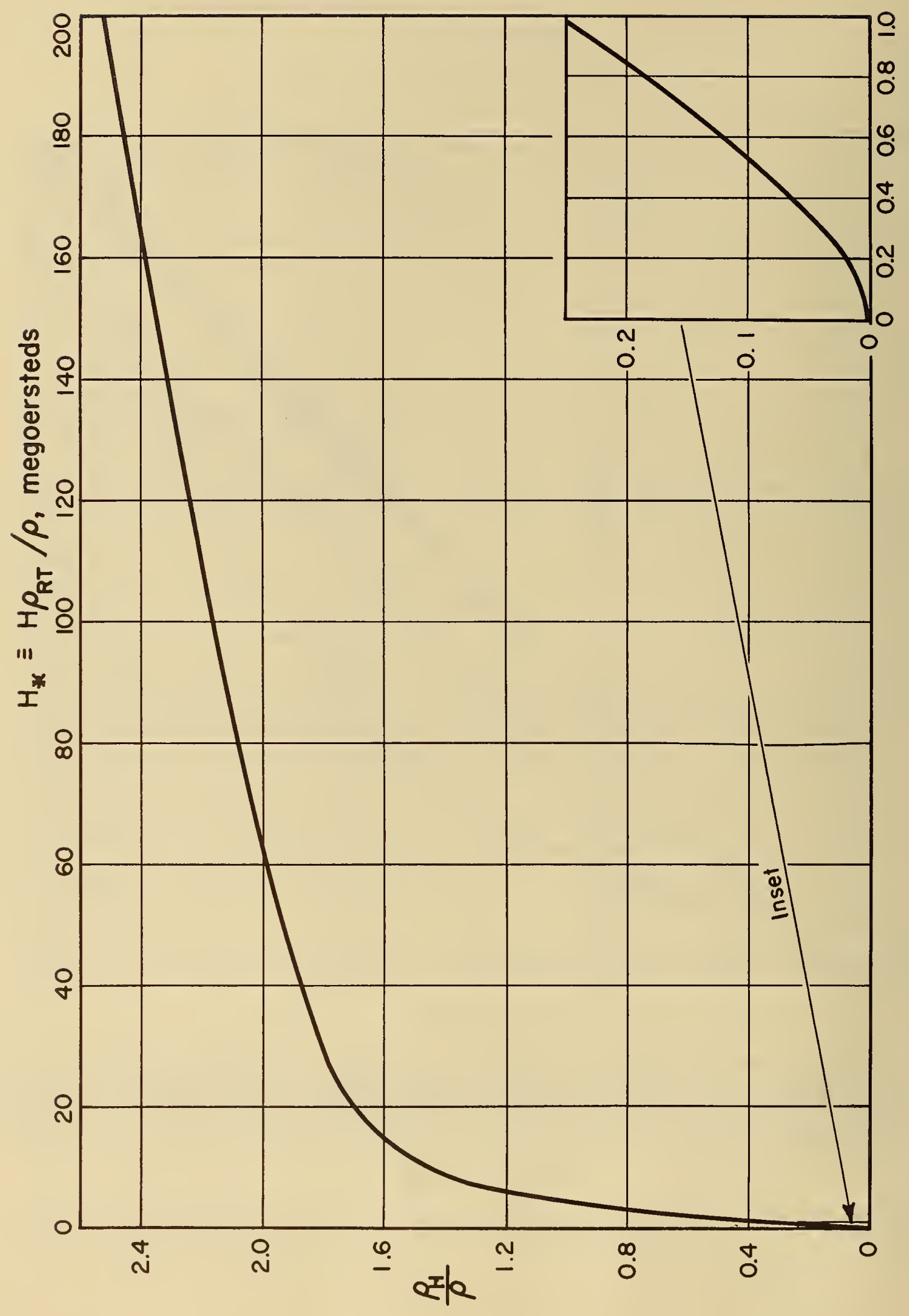

อ 


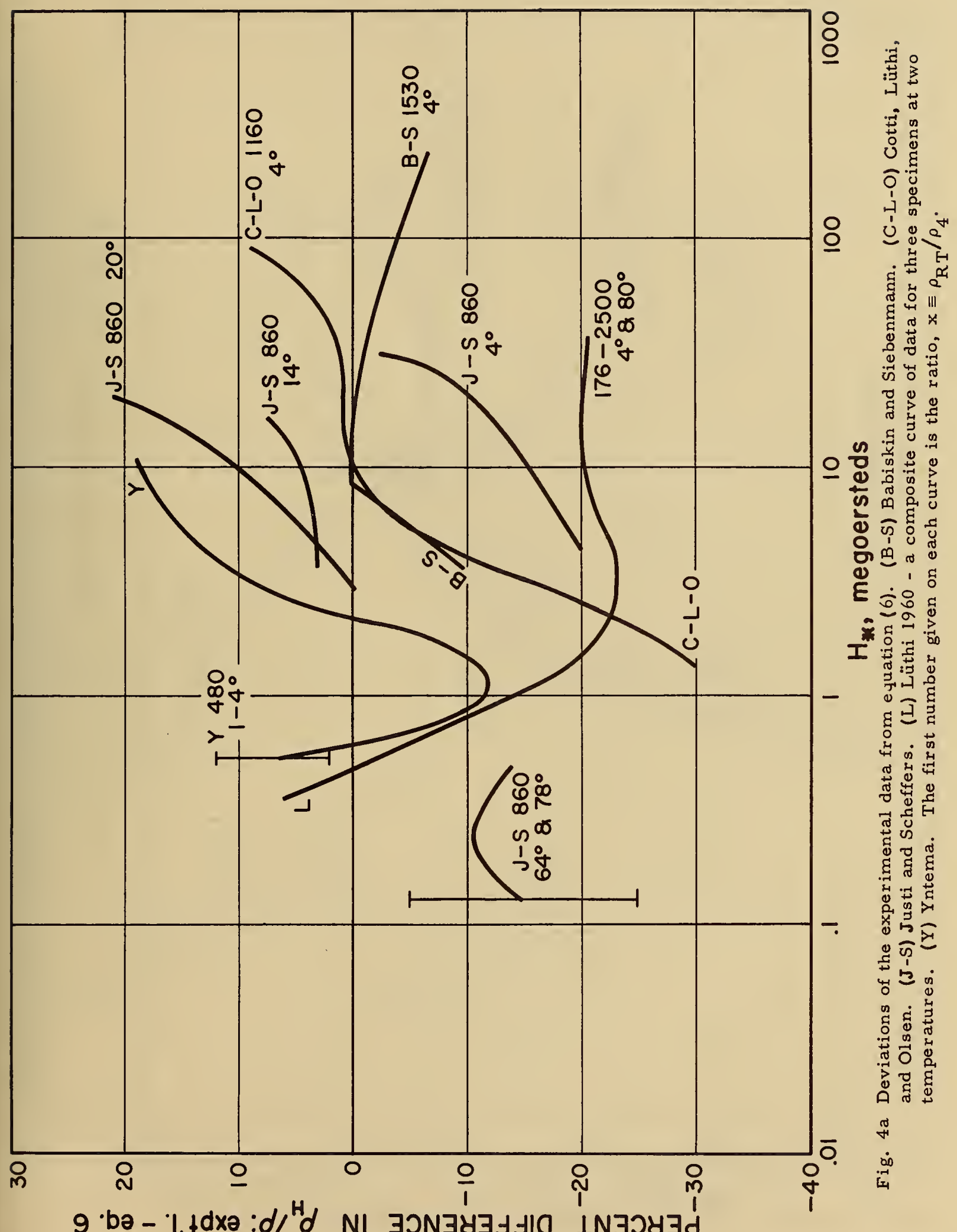




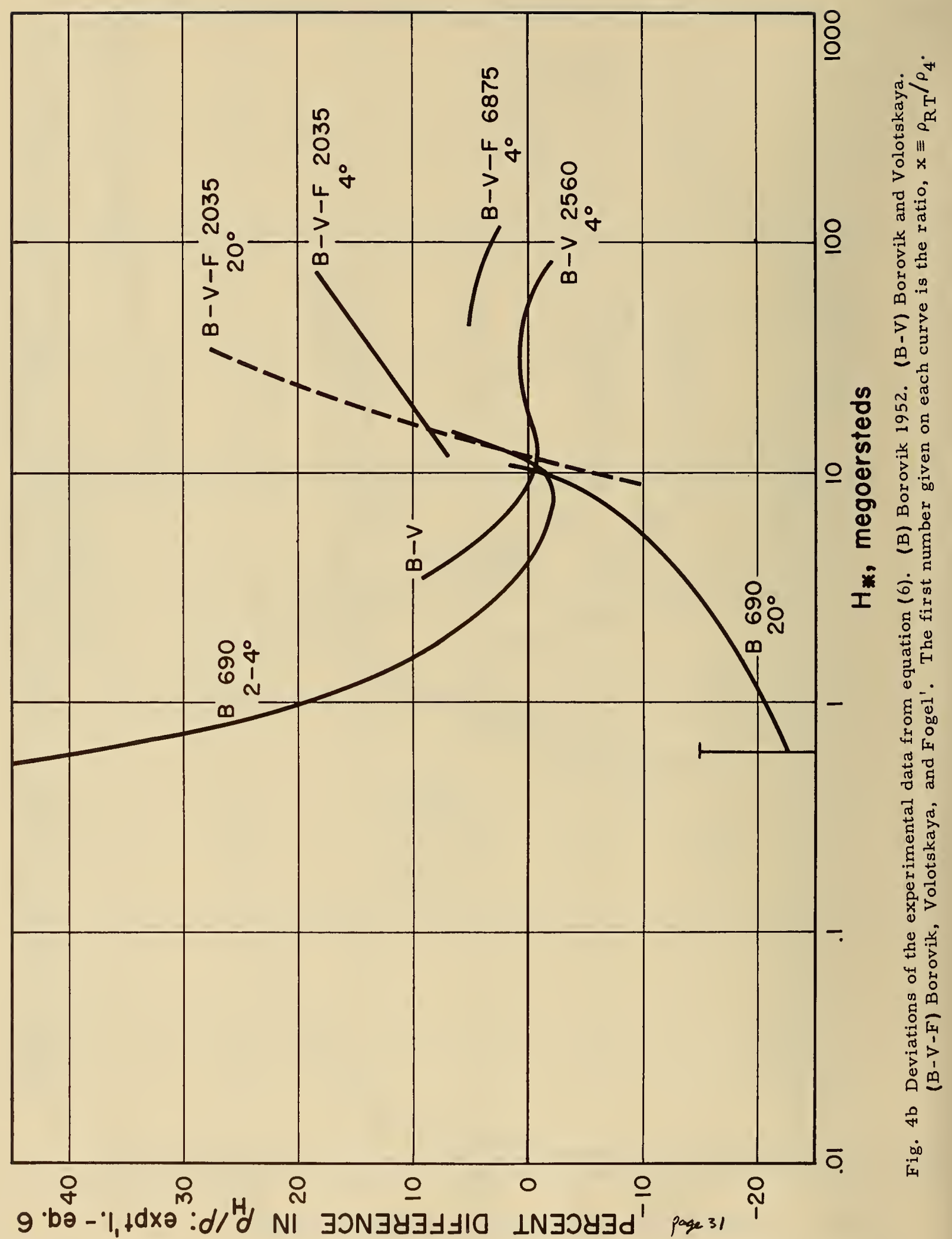




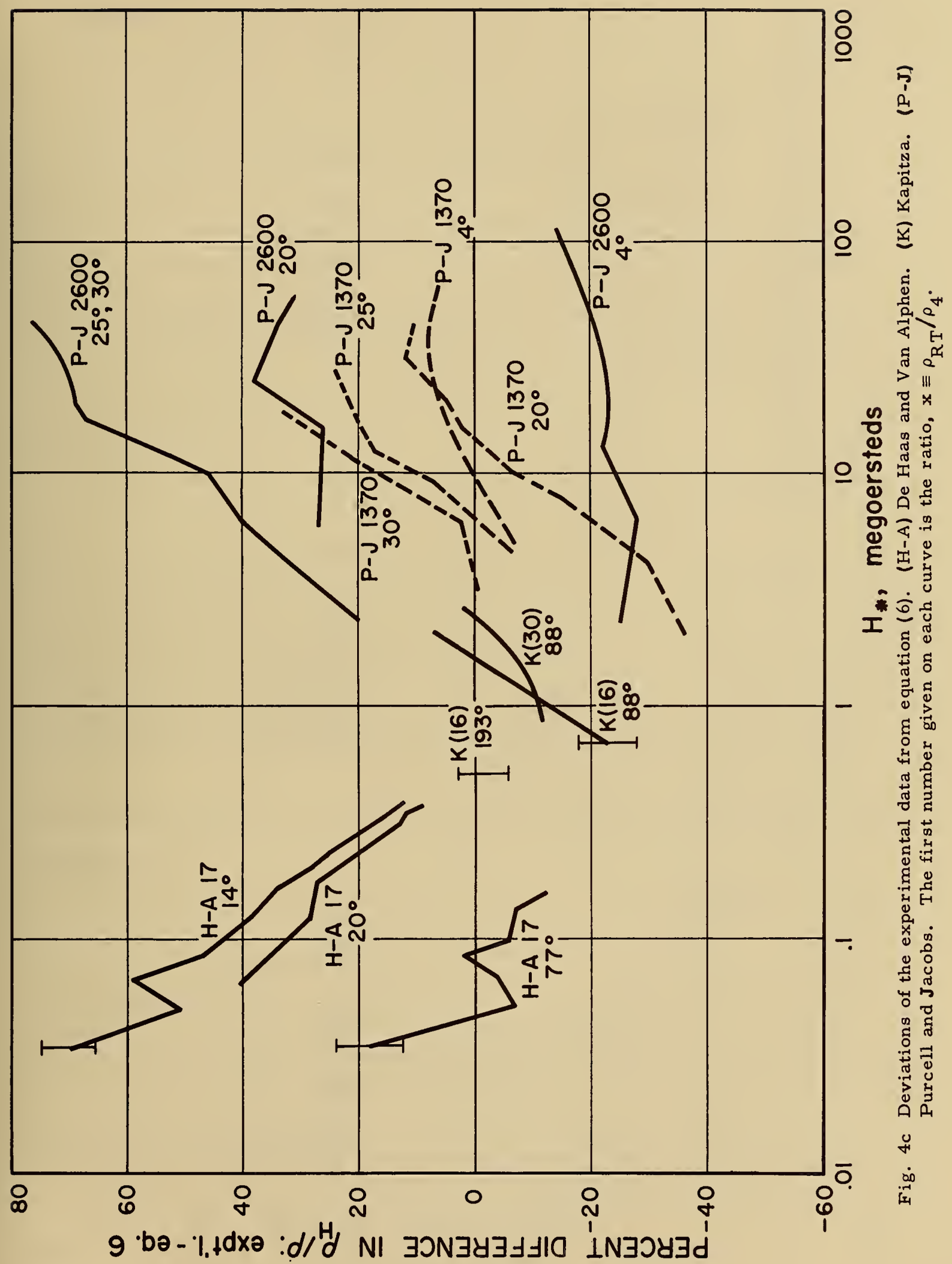




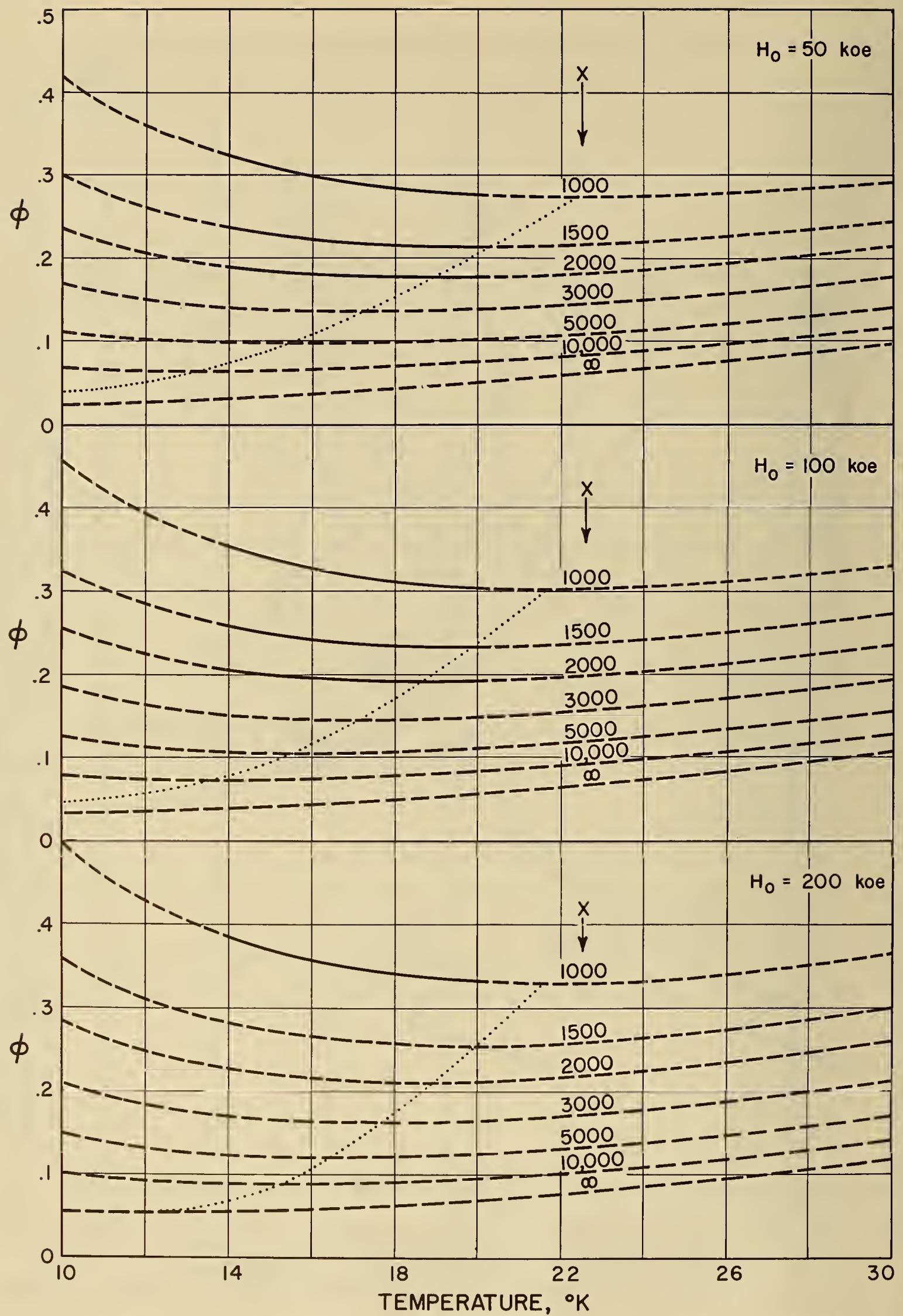

Fig. 5 Figure of merit of a long rectangular aluminum solenoid with $r_{2} / r_{1}=3$ for several values of residual resistance $r$ atio, $x$. Curves giving the loci of minima are also shown. 


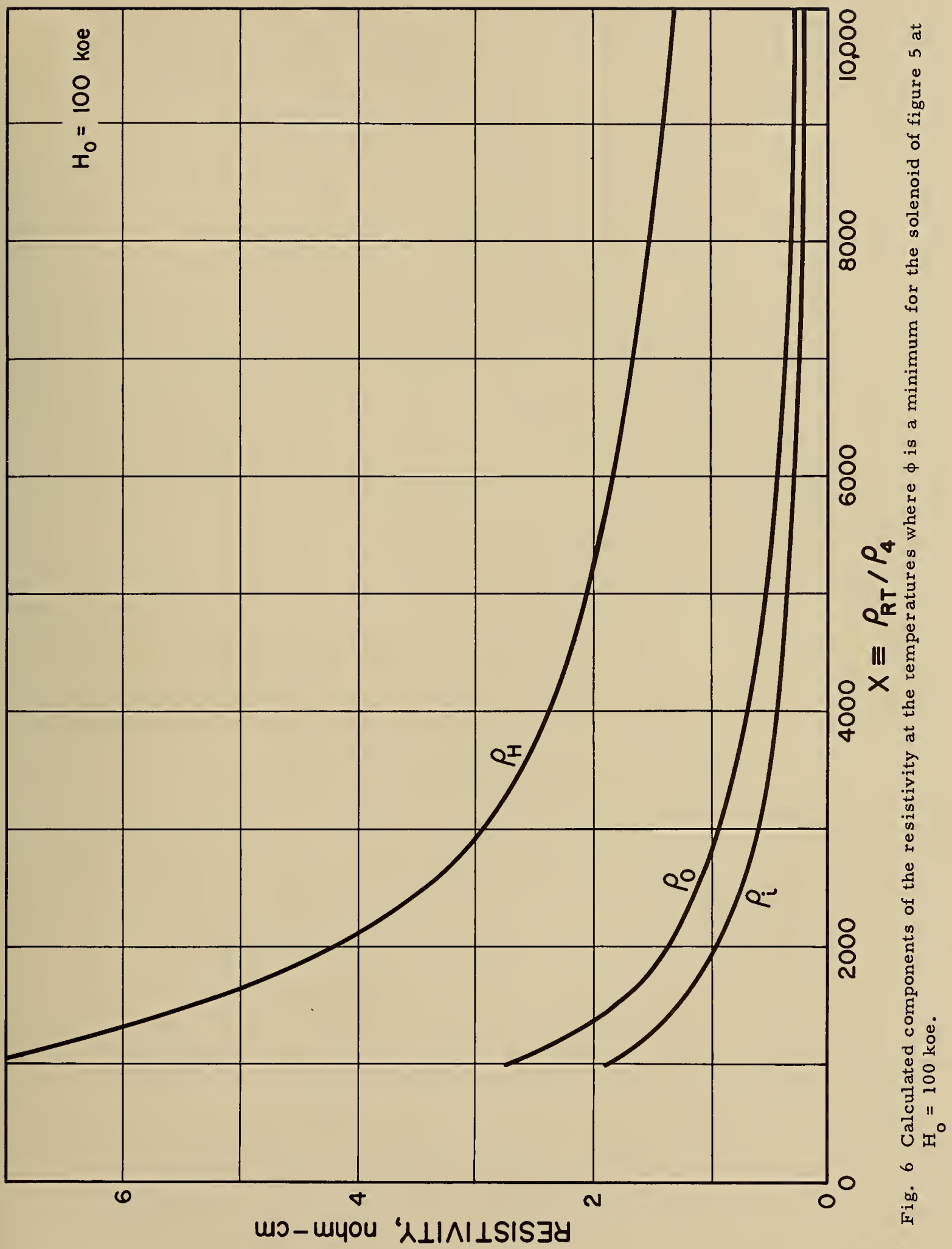



